\title{
Uma proposta de Cadastro Territorial para o Brasil
}

\section{A Cadastre proposal for Brazil}

\author{
Cesar Rogério Cabral ${ }^{1}$, Markus Hasenack ${ }^{2}$, Rovane Marcos de França ${ }^{3}$, Adolfo Lino de Araújo ${ }^{4}$ e Flávio Boscatto
}

1 Instituto Federal de Santa Catarina, Curso Técnico em Agrimensura, Florianópolis, Brasil. ccabral@ifsc.edu.br ORCID: https://orcid.org/ 0000-0003-4170-4410

2 Instituto Federal de Santa Catarina, Curso Técnico em Agrimensura, Florianópolis, Brasil. hasenack@ifsc.edu.br ORCID: https://orcid.org/0000-0003-4477-9143

3 Instituto Federal de Santa Catarina, Curso Técnico em Agrimensura, Florianópolis, Brasil. rovane@ @ifsc.edu.br ORCID: https://orcid.org/0000-0003-4867-6053

4 Instituto Federal de Santa Catarina, Curso Técnico em Agrimensura, Florianópolis, Brasil. adolfo.lino@ifsc.edu.br ORCID: https://orcid.org/0000-0001-7627-6060

5 Instituto Federal de Santa Catarina, Curso Técnico em Agrimensura, Florianópolis, Brasil. boscatto@ifsc.edu.br ORCID: https://orcid.org/0000-0002-8866-5140

Resumo: A implantação de um sistema cadastral deve objetivar o atendimento das necessidades de informações territoriais organizadas, bem como possibilitar a utilização do mesmo na geração de produtos que possam atender as multifinalidades que se apresentam para uma boa gestão municipal. No Brasil cada município procura manter um cadastro para fins fiscais, sendo as demais informações territoriais e jurídicas relativas as parcelas dispersas ou inexistentes. $\mathrm{Na}$ área rural a União vem realizando um cadastro com um conjunto de procedimentos legais e normativos para a realização do cadastro rural. Para a elaboração desta proposta foram elencadas premissas relativas aos aspectos jurídicos, técnicos e econômicos. O arranjo relativo aos objetos territoriais e as matrículas esclarecem e facilitam a adoção destas propostas para solucionar os problemas hoje enfrentados nos cadastros e já prevendo a adoção dos multipropósitos cadastrais. A estruturação deste cadastro passa por uma rede de referência, as precisões requeridas, as formas de levantamento, a cartografia cadastral, os produtos gerados e quem será o ente federativo responsável pela condução do processo. A implantação e a manutenção do cadastro são apresentadas em forma de fluxograma indicando claramente como o sistema irá funcionar. Ainda, destaca-se que todo o escopo da presente proposta se encontra em perfeita consonância com as premissas das novas versões das normas brasileiras que estão em processo de revisão e também procura viabilizar de maneira eficiente, econômica e tecnicamente segura para que seja possível a implantação e manutenção dos dados atualizados ao dia nos cadastros do Brasil.

Palavras-chave: Cadastro. Parcela. Estrutura do cadastro. Implantação e manutenção do cadastro.

\begin{abstract}
The implementation of a cadastral system aims to meet the needs of territorial information, as well as the generation of products that meet the multi-purpose that are presented for municipal management. In Brazil, each municipality seeks to maintain a cadastre for tax purposes, with the other territorial and legal information relating to the dispersed or nonexistent parcels. In the rural area, the Federal Government has been registering with legal and regulatory procedures. For the elaboration of this proposal, premises related to legal, technical and economic aspects were listed. The arrangement regarding territorial objects and enrollments clarify and facilitate the adoption of these proposals to solve the problems faced today in the cadastres and already foreseeing the adoption of cadastral multipurposes. The structuring of this cadastre goes through a reference network, the required accuracy, the forms of survey, the cartography registration, the products generated and who will be the federative entity responsible for conducting the system. The implementation and maintenance of the land registry are presented in the form of a flow chart clearly indicating how the system should work. It is also noteworthy that the present proposal is perfectly in line with the premises of the new versions of the Brazilian technical standards that are in the process of being revised and also seeks to enable an efficient, economical and technically safe way for implementation and maintenance to be possible data updated daily in the cadastre of Brazil.
\end{abstract}

Keywords: Cadastre. Parcel. Cadastre structure. Implementation and maintenance of the cadaster. 


\section{INTRODUÇÃO}

A implantação de um sistema cadastral deve objetivar ao atendimento das necessidades de informações territoriais organizadas, bem como possibilitar a utilização do mesmo na geração de produtos que possam atender as multifinalidades que se apresentam para uma boa gestão municipal.

Embora não se tenha no Brasil um sistema cadastral propriamente dito, reconhece-se que a Lei Federal 10.267/2001 (BRASIL, 2001), conhecida como a Lei do Georreferenciamento de Imóveis Rurais, é o grande marco legal brasileiro em termos de Cadastro Territorial e que o conteúdo dos seus artigos, e posteriormente dos decretos que a regulamentaram, foi fortemente inspirado e apoiado nos princípios cadastrais propagados pela Federação Internacional dos Geômetras - FIG.

A visão de futuro para o Cadastro apresentada pela FIG na década de 1990 estava contida nas seis declarações do documento Cadastro 2014, quais sejam: i) Situação completa do território incluindo direitos e restrições, ii) Integração entre dados cartográficos e registrais, iii) Substituição da cartografia cadastral por modelos de dados, iv) Soluções para dados cadastrais digitais, v) Favorecimento das parcerias públicoprivadas, e vi) Cadastros autossustentáveis. Em diferentes graus, as declarações nortearam a implantação e modernização de sistemas cadastrais em todo o mundo e não parecem ter perdido sua validade (FIG, 1995; KAUFMANN; STEUDLER, 1998).

No Brasil, esta visão futurista para o Cadastro chegou em meados da década de 2000 e impactou a lei 10267/2001 que trouxe para o cenário nacional diversos conceitos cadastrais preconizados pela FIG, tais como: parcela, vértice definidor de parcela, precisão e tolerância das coordenadas dos vértices definidores, código unívoco de parcela, rede de referência cadastral, normatização de métodos de levantamentos cadastrais, completude cadastral, execução do cadastro ao longo do tempo, atualização cadastral, procedimentos de acreditação/certificação, entre outros. O presente trabalho compartilha esta visão e busca aplicá-la em suas propostas.

A referida lei, os decretos regulamentadores, a norma e os manuais técnicos que a subsidiam possuem algumas limitações. De um lado o seu alcance é restrito aos imóveis rurais, de outro, existe um conjunto de fragilidades que ainda carecem de aprimoramento (ARAÚJO et al., 2018). Entretanto, as suas boas práticas sedimentadas ao longo de quase 20 anos de aplicação podem e devem ser aproveitadas quando se busca esse ajuste conceitual a fim de definir os elementos de um Cadastro Territorial para o Brasil. Duas destas boas práticas são fundamentais neste sentido: o mecanismo de certificação de parcelas e a correspondência entre parcelas certificadas e matrículas.

Mais recentemente, a FIG tem divulgado uma outra visão sobre Cadastro, um tanto mais abrangente, que reconhece as particularidades de cada local em relação ao grau de maturidade (ou até a inexistência) do sistema cadastral e as condições legais e estruturais para a sua implantação e/ou modernização. Os princípios de fit-for-purpose land administration estão baseados em três eixos de ação: o foco no propósito de atendimento às necessidades locais de gestão territorial, um design espacial flexível para o Cadastro, e as melhorias incrementais para continuidade e aplicabilidade (FIG, 1995; FIG, 2015; ONU, 2016).

A definição dos elementos mínimos e necessários de um Cadastro Territorial para o Brasil é uma tarefa desafiadora, que passa por uma revisão conceitual em alguns pontos, haja vista que muito já foi apresentado em publicações de periódicos, dissertações e teses sobre o assunto. Faz-se necessário, ao mesmo tempo, olhar para trás para capturar a essência do tema, compreender a atualidade para garantir viabilidade e projetar adiante para assegurar sustentabilidade.

Neste sentido, a proposta do presente trabalho busca harmonizar mais de 30 anos de pesquisa sobre o Cadastro no Brasil, com atendimento aos princípios e conceitos cadastrais da FIG e ao arcabouço legal e de conjuntura cadastral nacional. Os capítulos que se seguem estão assim dispostos: O Capítulo 2 apresenta a situação do Cadastro Territorial no Brasil; o Capítulo 3 elenca o conjunto de premissas técnicas necessárias que devem ser atendidas na estruturação um sistema cadastral adequado às condições técnicas e jurídicas existentes, além de sugestão de adoção de outras medidas que visem a melhorar e aperfeiçoar o sistema; o Capítulo 4 apresenta uma discussão acerca do conceito de parcela e objetos territoriais (e suas relações com a matrícula) e uma proposta de definição para ambos, adequada à nossa realidade; o Capítulo 5 aborda a necessidade da rede de referência, a necessidade de atualização normativa e as sugestões para tal; o Capítulo 
6 apresenta o arranjo proposto e o fluxo de funcionamento para o sistema cadastral; e, por fim, o Capítulo 7 apresenta o conjunto de conclusões do trabalho.

\section{A SITUAÇÃO DO CADASTRO TERRITORIAL NO BRASIL}

Idealmente todo município brasileiro deveria ter um Cadastro Territorial, cobrindo a totalidade de seu território, para os fins a que este se destina, porém, não existe previsão legal para que isto aconteça. $\mathrm{O}$ município, então, fica na dependência que a sua equipe de gestores entenda dos propósitos e benefícios que um Cadastro Territorial, minimamente organizado, vai proporcionar aos munícipes. Santos e Antunes (2020) em pesquisa em oito municípios sobre regularização fundiária constataram a inexistência de cadastro nestas áreas dificultando a realização dos trabalhos e a diminuição dos custos envolvidos no processo.

Cada município procura manter um cadastro para fins fiscais, visando a arrecadação de impostos na área urbana, como principal foco e objetivo do sistema. Para isto, os limites dos imóveis são levantados por sensoriamento remoto e recebem um código denominado inscrição imobiliária, além de informações necessárias à composição das equações para a determinação do valor do imposto, sendo as demais informações territoriais e jurídicas relativas às parcelas dispersas ou inexistentes.

Entre as municipalidades, a primeira situação que se pode apontar é referente à total ausência do cadastro para qualquer finalidade, nem sequer a informação para a cobrança de tributos relativos à propriedade. Nenhuma informação espacial é utilizada para o gerenciamento municipal.

A segunda situação é aquela em que uma parte do município, normalmente as áreas mais urbanizadas e valorizadas, dispõe de um cadastro minimamente organizado para o cumprimento das funções fiscais. Nestes casos é possível encontrar plantas de quadra em papel e um banco de dados das informações suficientes para a cobrança de impostos. Em outros raros casos, possuem um sistema de informações com a cartografia em meio digital.

O terceiro grupo de cidades tem um cadastro compondo o que se denomina cadastro multifinalitário com várias informações disponíveis aos gestores e a população em geral, com setores específicos para atualizar, e em alguns casos até desenvolver, seus sistemas de informação. Dentro deste grupo, uma pequena parte consegue integrar os vários setores que necessitam da informação espacial e também ampliam suas redes de referência cadastral, não se limitando aquela que foi implantada na confecção do cadastro.

Outro componente fundamental quando se pensa em Cadastro Territorial é o sistema de registro de imóveis, que está implantado em todo o país, organizado em circunscrições imobiliárias que cobrem tanto a área urbana quanto a rural. Para efeitos de registros, a propriedade recebe um número denominado matrícula e nela são anotadas algumas características dos imóveis que em tese deveriam ser fruto de um levantamento executado in loco por topografia. A relação proposta entre parcela e matrícula será abordada mais adiante no capítulo 4.

A base física do registro é o imóvel material, ou seja, a área de terra delimitada. Segundo Mello (2006) a matrícula representa a individualidade do imóvel, sua situação geográfica e perfeita descrição, sofrendo alterações objetivas e subjetivas através de averbações.

O Cadastro Territorial e o Registro deveriam um espelhar o outro, ou seja, o registrado é o cadastrado e vice-versa. Como isto não acontece, os registradores vêm buscando soluções para especializar as matrículas criando um cadastro próprio do que está matriculado. Ressalta-se que os memoriais descritivos mais recentes possuem coordenadas definidoras dos limites dos imóveis que são levadas a registro. Também os dois números identificadores do imóvel, matrícula no registro de imóveis e inscrição imobiliária na prefeitura, que deveriam constar em ambos nem sempre refletem o mesmo objeto.

$\mathrm{Na}$ área rural a União vem realizando um Cadastro Territorial com um conjunto de procedimentos legais e normativos para a realização do cadastro rural, através do georreferenciamento de imóveis rurais, mas que também possui informações dispersas e incompletas tendo em vista um sistema cadastral funcional e autossustentável. O sistema certificador de imóveis rurais ainda possui fragilidades, porém é um exemplo a ser analisado do que pode funcionar para os cadastros no Brasil.

Para Araújo et al. (2018) como benefícios do avanço, pode-se citar a agilidade nos processos de certificação, a padronização nas descrições dos imóveis e parcelas, além de dar ao profissional habilitado a 
devida responsabilidade do trabalho realizado.

Além do cadastro territorial rural, a União mantém outros cadastros relativos ao território e às áreas por ela controladas. A Secretaria do Patrimônio da União (SPU) que deveria por competência administrar os bens da União estabelecidos no artigo 20 da Constituição Federal (BRASIL, 1998), não possui um cadastro territorial com as informações sobre a totalidade destes bens.

A SPU vem tentando realizar as demarcações e homologação de duas importantes definições de divisão territorial que afetam milhares de pessoas por sua indefinição tanto jurídica quanto posicional, que são as linhas que definem os Terrenos de Marinha e a Linha Média das Enchentes Ordinárias.

Também mantêm cadastros próprios ou informações territoriais no âmbito da União: a Fundação Nacional do Índio ( FUNAI), o Instituto Brasileiro de Geografia e Estatística ( IBGE), o Ministério do Meio Ambiente, a Receita Federal, a Secretaria Especial de Assuntos Fundiários, o Departamento Nacional de Infraestrutura de Transportes (DNIT), estatais de energia, entre outras agências do poder executivo.

Os estados também executam ou mantém cadastros através de seus Institutos de Terras, ou departamentos fundiários e das Secretarias de Meio Ambiente realizando levantamentos para fins de regularização fundiária, discriminação de terras públicas e solução de conflitos fundiários e cadastro ambiental, tanto em áreas rurais quanto urbanas.

As companhias responsáveis por serviços de infraestrutura como saneamento e energia mantêm cadastros com as mesmas informações territoriais que as prefeituras. Também elaboram normas técnicas para levantamento e execução destes cadastros de forma unilateral para atender tão somente suas finalidades.

A rede de referência cadastral que é o elemento garantidor da geometria e da precisão dos levantamentos, que deveria ser única para todas as finalidades do cadastro, quando existente, é realizada de forma independente e individualmente pelas entidades governamentais citadas, cada qual tentando resolver seu problema ignorando as redes já implantadas.

A unificação dos elementos básicos do Cadastro Territorial certamente facilitaria o compartilhamento de informações, reduziria os custos de execução, manutenção e atualização e ainda possibilitaria a ampliação das multifinalidades a que se propõe um cadastro moderno. Enquanto se discute cadastros 3D, colaborativos, acessíveis, os municípios não conseguem realizar o básico Cadastro Territorial 2D.

\section{PREMISSAS PARA O CADASTRO}

O instrumento legal que autoriza a implantação de tal sistema cadastral territorial nos municípios brasileiros é contemplado pelo inciso VIII, Art. 30, da Constituição da República, promulgada em 5 de outubro de 1988, que responsabiliza o município na construção, consolidação e manutenção, o qual afirma que: "compete aos municípios, entre outras obrigações, promover, no que couber, adequado ordenamento territorial mediante planejamento e controle do uso, parcelamento e da ocupação do solo urbano."

$\mathrm{O}$ adequado ordenamento territorial somente é viável mediante o conhecimento preciso do território administrado e a condição para tal passa obrigatoriamente por um Cadastro Territorial perfeitamente integrado com o Registro de Imóveis.

De modo a nortear uma proposta viável de implantação de um Cadastro Territorial para o Brasil, foram elencadas algumas premissas, que devem ser atendidas para que se possa estruturar um sistema cadastral adequado às condições técnicas e jurídicas existentes, assim como a adoção de outras medidas que visem a melhorar e aperfeiçoar o sistema, quais sejam:

- Premissa 1: O Cadastro deve ser parcelar, num sistema básico comum que serve, com exclusividade, apenas para a identificação da parcela territorial para a comprovação oficial dos seus limites (PHILIPS, 2004). A parcela territorial é a unidade básica do Cadastro Territorial (FIG, 1995).

- Premissa 2: A existência de Rede de Referência. Condição básica do cadastro, densificada ao nível de levantamentos de limites legais apoiados em uma norma técnica, fundamentada no Sistema Geodésico Brasileiro. A norma NBR 14.166 (ABNT, 1998) trata do procedimento para implantação da rede de referência Cadastral Municipal. Atualmente, tal norma está sendo reestruturada, ainda sem data para consulta pública.

- Premissa 3: O Cadastro Territorial por medição em campo. O levantamento dos vértices definidores das parcelas deve ser executado in loco por medição de campo, apoiado na rede de referência com as precisões 
propagadas, atendendo tolerâncias previstas em normas técnicas, como ocorre nos países de referência na área. O levantamento para o Cadastro Territorial deve ser por medição de campo sobre cada vértice definidor da parcela uma vez que os seus limites legais são invisíveis e não representam as feições reais (pseudolimites representados geralmente por cercas e muros) existentes em campo e que materializam a ocupação de fato do território.

- Premissa 4: A demarcação dos vértices dos imóveis. Todos os vértices dos imóveis devem ser demarcados sempre que visíveis, acessíveis, estáveis e conveniente. A materialização dos vértices dos imóveis deve ser indicada nos originais de levantamentos de campo (croquis) e na carta cadastral. A materialização dos vértices dos imóveis deve atender a finalidade quanto à durabilidade, pois eles são a certeza de que uma nova medição de verificação seja realizada fisicamente sobre o mesmo vértice para dirimir dúvidas futuras. O vértice permanecendo demarcado em campo é forte indício que não sofreu mudança na posição por reconstrução da feição onde ele foi materializado, como muros, cercas e edificações, por exemplo.

- Premissa 5: A previsão para multifinalidades do Cadastro Territorial. O cadastro das parcelas territoriais deve servir de base geométrica e legal (oficial) para os outros cadastros temáticos que formam em conjunto um Cadastro Territorial Multifinalitário. São exemplos de cadastros temáticos os de infraestrutura, fiscal, ambiental, geotécnico, logradouros, ocupação do solo, entre outros.

- Premissa 6: A integração entre Registro de Imóveis e o Cadastro Territorial. O princípio da especialidade do Registro de Imóveis e a observação do direito de propriedade são atendidos quando, na caracterização espacial do imóvel envolvendo sua localização e dimensões, não hajam lacunas e nem superposições considerando a totalidade do território. A precisa caracterização espacial do imóvel passa obrigatoriamente por um Cadastro Territorial que deve ser interconectado com o Registro de Imóveis.

- Premissa 7: A necessidade de profissionais habilitados e credenciados para a execução dos levantamentos. Os profissionais que executarão o cadastro devem ter formação compatível com as suas habilitações estabelecidas pelos conselhos profissionais.

- Premissa 8: O aproveitamento de normas técnicas existentes. Existe atualmente um conjunto bastante significativo de leis e normas técnicas, tanto da ABNT quanto de entidades regulamentadoras, que já são difundidas e de conhecimento dos profissionais e que deverão ser aproveitadas para a execução desta proposta.

- Premissa 9: As precisões posicionais dos levantamentos. Definidas em normas técnicas de forma a serem compatíveis com a realidade e sustentadas tecnicamente.

- Premissa 10: A utilização de produtos de sensores remotos, mais apropriada aos levantamentos em massa, diminuindo os custos na elaboração de cartas de feições que podem ser aproveitadas para a criação de parcelas provisórias (parcelas não certificadas, conforme será abordado mais adiante), aproximação inicial para um Cadastro Territorial.

- Premissa 11: O aproveitamento dos cadastros municipais fiscais, que são elaborados considerando a ocupação de fato do território e não a jurídica e tem como chave de localização a inscrição imobiliária. Igualmente aos produtos de sensores remotos podem ser aproveitadas para a criação de parcelas provisórias.

\section{PARCELA E OBJETOS TERRITORIAIS}

Ao longo das últimas décadas, desde que o tema Cadastro tem sido debatido no Brasil, busca-se uma adequação dos vários conceitos e conteúdos relacionados ao Cadastro Territorial, de forma que se possa adotar uma estrutura ou modelo cadastral em nosso país.

Qualquer tentativa deve levar em consideração as premissas técnicas já elencadas nos capítulos anteriores e vislumbrar que para cumprir as suas finalidades e ser viável o Cadastro Territorial para o Brasil deverá ser, necessariamente, flexível, simples, completo e atualizado.

Esta afirmação não implica em descartar os conceitos internacionalmente aceitos e sedimentados de Cadastro, pelo contrário, os princípios cadastrais que nortearam os países mais desenvolvidos nesta área devem ser observados, estudados e ajustados à nossa realidade para que aqui se possa produzir resultados semelhantes aos alcançados internacionalmente.

De forma a adequar os conceitos à nossa realidade e oferecer a posição dos autores acerca do assunto, apresenta-se a seguinte definição da parcela: 
A parcela é a unidade do Cadastro Territorial, constitui uma porção territorial de extensão contínua, definida por seus vértices de limite.

Esta definição está em consonância e atende aos princípios cadastrais internacionais além de ser suficientemente ampla e flexível para abarcar as mais diversas situações nas quais se possa modelar a existência de parcelas (Capítulo 3, Premissa 1).

A continuidade espacial da parcela referida na definição acima é um conceito com relação com a unidade dominial, as causas jurídicas que a originam (imóvel registrado ou não, existência de títulos de domínio, entre outros) e a localização político-administrativa (estado, município), conforme discutido em França et al. (2018a) e Brandão (2003). Em relação aos vértices de limite definidores da parcela, estes devem ter coordenadas georreferenciadas e a parcela deve receber um código de identificação que seja único (não se repete em outra parcela), inequívoco (identifica perfeitamente a parcela e não se confunde com outros tipos de códigos) e estável (permanece vinculado a parcela no tempo, quando esta sofre alteração nos limites novo código lhe é atribuído).

Em termos de simplicidade conceitual aplicada ao Cadastro Territorial, destaca-se a solução dada pela Lei Federal 10.267/2001 (BRASIL, 2001), para a qual o conceito de imóvel (rural, no caso) adotado é o mesmo da lei de Registros Públicos, Lei Federal 6.015/1973 (BRASIL, 1973), o que simplificou imensamente o entendimento de parcela e a sua adequação à legislação territorial em vigor no Brasil, além de promover efetivamente a integração cadastro registro. O conceito da lei 10.267/2001 para parcela é o de que esta deve corresponder à matrícula e, por consequência, ao imóvel. Para os fins previstos em lei, parcela, imóvel e matrícula correspondem a um mesmo objeto (BRASIL, 2013a).

Na base de dados cadastrais do INCRA, que é o órgão gestor do cadastro territorial rural, há apenas parcelas que passaram por um processo de certificação (Figura 1). Conforme será abordado mais adiante, essa compreensão pode ser ampliada admitindo tipos diferentes de parcelas. Entretanto, esta prática do cadastro territorial rural tem se mostrado capaz de promover a integração cadastro registro com simplicidade conceitual e adequação legal, e deve nortear a estruturação de um modelo cadastral viável que abarque tanto parcelas rurais como parcelas urbanas.

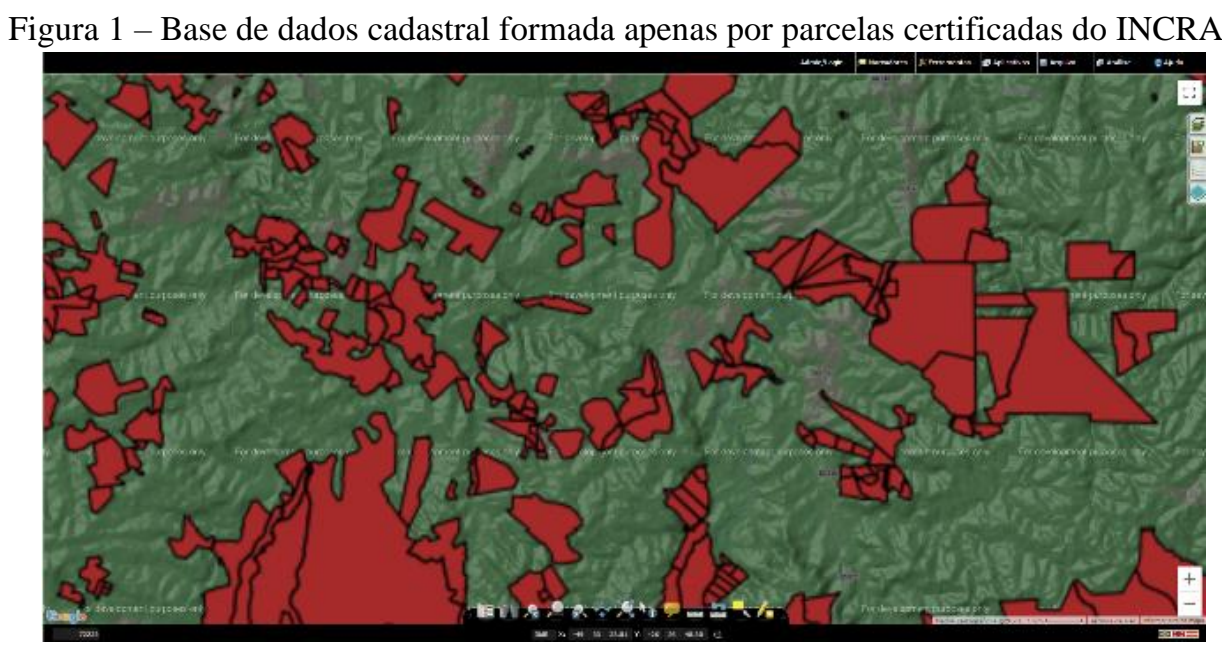

Fonte: INCRA (2020).

Tal entendimento advindo da experiência rural, apoiado na legislação em vigor, de que para o Cadastro no Brasil se tornar viável deve haver algum tipo de correspondência entre parcela (elemento do cadastro) e matrícula (elemento do sistema registral), conduz forçosamente a uma importante propriedade: parcelas são bidimensionais. Desta forma, termos como territorial, bidimensional e 2D devem estar associados à compreensão do que é parcela. A Figura 2 apresenta uma imagem típica de ocupação urbana e a respectiva definição de parcelas territoriais, ou seja, 2D. Toda a sorte de ocorrências territoriais acima ou abaixo da superfície, cuja complexidade extrapolem as duas dimensões, deve ser modelada na forma de objetos territoriais, cuja definição será apresentada um pouco mais adiante. 
Figura 2 - Exemplo de ocupação territorial (esquerda.) e parcelas territoriais correspondentes (direita.).

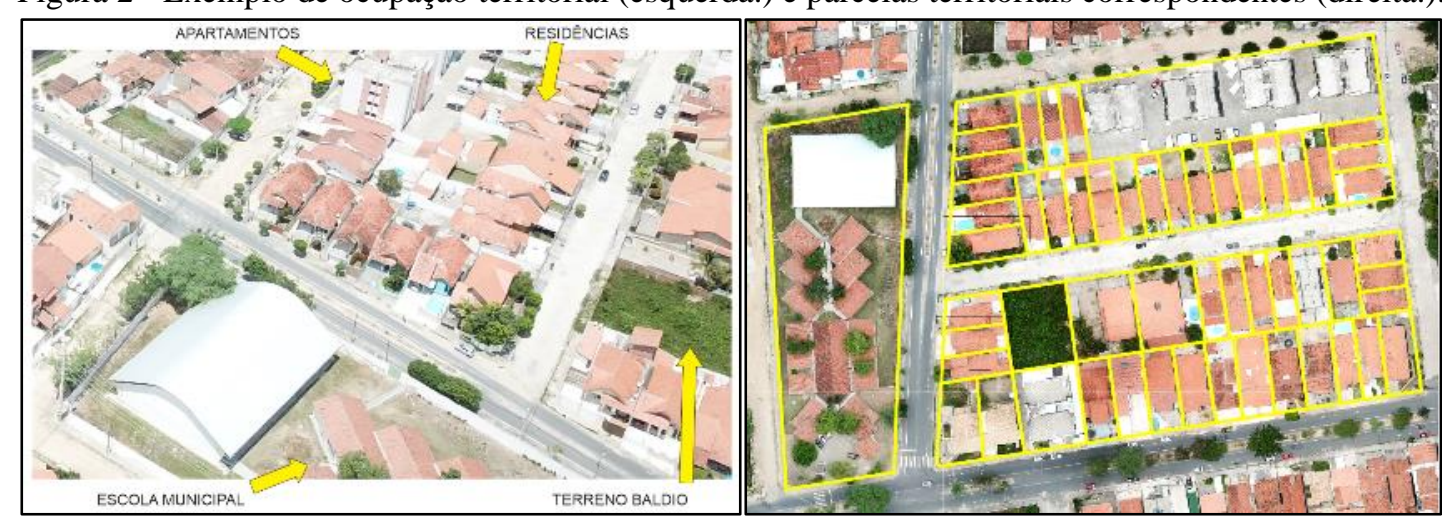

Fonte: Os autores (2020).

A correspondência entre parcela e matrícula é um princípio, o que não significa que toda parcela necessariamente está relacionada a uma matrícula e vice-versa, haja vista que ocorrem situações nas quais parcelas não possuem matrícula (áreas de posse, áreas públicas, vias, etc.), como também algumas matrículas podem se referir a elementos acima ou abaixo da superfície, não necessariamente correspondendo a parcela, mas estando ligadas a esta (unidades em condomínios verticais, direito de laje, etc.).

Com vistas a expandir e adequar estes conceitos, de forma que tanto parcelas no meio urbano como rural possam ser abarcadas (completude cadastral), atender às características particulares de gestão territorial rural (centralizada no INCRA) e urbana (pulverizada nas mais de 5500 prefeituras municipais), além de promover a atividade fim do Cadastro Territorial (ligar pessoas e terra), faz-se preciso caracterizar dois tipos de parcelas para o Cadastro no Brasil: parcelas certificadas e parcelas não certificadas.

A parcela certificada é aquela cujos limites foram verificados in loco, através de medições em campo por agrimensura, representando os limites legais ou de fato para que se torne possível levá-la a registro quando necessário, ou seja, que os limites desta parcela correspondam à descrição constante em uma matrícula e viceversa (Capítulo 3, Premissas 3, 4, 7 e 8). Este é o procedimento comum aplicado às parcelas do cadastro territorial rural, cujo processo carece apenas de um aperfeiçoamento. A parcela só deve ser considerada certificada, após passar por um processo que assegure o atendimento a dois critérios: i) a não sobreposição e ii) a não existência de lacunas entre parcelas certificadas contíguas (atualmente, a certificação aplicada ao cadastro rural do INCRA atende apenas ao primeiro critério, conforme discutido em Araújo, et. al (2018)). Para atendimento do segundo critério, existe a necessidade prévia de saber quais são as parcelas confrontantes, mesmo que ainda não certificadas.

As parcelas certificadas são o elo do Cadastro Territorial com o sistema registral (Capítulo 3, Premissa 6) e tem como finalidade o consequente fortalecimento da segurança jurídica dos títulos que lhes correspondem (as matrículas), tendo, portanto, um caráter definitivo (no sentido de ser distinto do caráter provisório das não certificadas).

A origem das parcelas certificadas está nos levantamentos exigidos pelos órgãos de gestão do cadastro (o INCRA para o rural, as prefeituras para o urbano) ou pelo registro de imóveis com anuência daqueles para uma infinidade de processos que envolvem questões legais, de agrimensura (Capítulo 3, Premissa 7). Estes levantamentos são bem aproveitados no caso do cadastro rural, já que são normatizados e integram um sistema, porém são subutilizados no cadastro urbano, ou atendem brevemente uma exigência específica (um alvará de construção, uma licença ambiental, uma análise de viabilidade de uso do solo, um processo de usucapião, desmembramento, remembramento, etc.), para depois serem descartados, quando deveriam servir também e principalmente para atualizar a base cadastral. Um protocolo pouco sofisticado, porém mais eficiente de troca de informações, faria com que prefeituras e cartórios de registro de imóveis mantivessem um ao outro sempre atualizado.

A parcela não certificada é aquela oriunda das bases de dados geoespaciais existentes, normalmente delimitadas por métodos de levantamento em massa, ou aquelas que ainda não passaram por processo de certificação (Capítulo 3, Premissa 10). Os limites da parcela não certificada não foram verificados in loco e tem, portanto, a confiabilidade que a fonte de dados lhes proporciona. Em concordância com o exposto, França 
et. al (2018b) elenca uma série de problemas críticos devido às divergências na interpretação das feições que aparentemente definem os limites de parcelas. No estudo do referido autor, foram realizados voos com uma aeronave remotamente pilotada (RPA) e foi executada a restituição das feições sobre as ortofotos geradas. Um dos resultados (Figura 3) mostra um conjunto de parcelas com discrepância posicional e outro conjunto de parcelas, ambas não certificadas, com delimitações distintas quando comparadas a restituição das feições sobre as ortofotos e a base de dados do cadastro fiscal fornecida pela Prefeitura Municipal de Florianópolis-SC. Os autores indicam que os mesmos tipos de discrepância foram encontrados quando comparadas estas fontes de dados com as matrículas dos imóveis em questão.

Figura 3 - Parcelas com discrepância posicional (A) e parcelas com delimitações distintas (B).

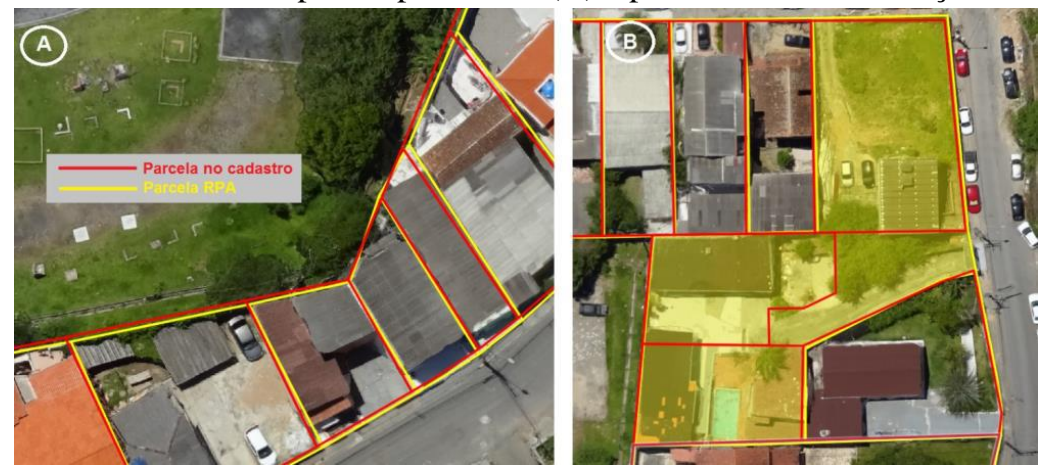

Fonte: França et al. (2018b).

Comumente as administrações municipais dispõem de bases de dados geoespaciais do território urbano que foram levantadas em massa ou originadas de projetos de loteamentos. Estas bases de dados cobrem toda a extensão ou parte do perímetro urbano e foram confeccionadas por restituição aerofotogramétrica, por imagens de satélite, mapas antigos, levantamentos para diversas finalidades principalmente atender aos objetivos fiscais para o lançamento de impostos territoriais (como o IPTU, o ITBI, e outros), expedição de licenças, alvarás, entre outros. São os chamados cadastros fiscais, econômico, técnico, imobiliário, tributário e mais uma gama de denominações atribuídas. Tais fontes de dados podem ser aproveitadas para a delimitação de parcelas do tipo não certificadas (Capítulo 3, Premissa 11).

As parcelas não certificadas têm caráter provisório (ou seja, existem até serem sucedidas por outra de caráter definitivo) e podem ser alteradas administrativamente (divididas ou agrupadas, modificadas geometricamente, apagadas ou criadas, e assim por diante) como já ocorre atualmente nos diversos processos realizados nas prefeituras municipais sobre as suas bases de dados geoespaciais existentes. Progressivamente elas devem ser sucedidas por parcelas certificadas em um fluxo que será abordado mais adiante neste trabalho.

O estudo impetrado por França et al. (2018b) ainda apresenta um exemplo concreto de como pode se dar a substituição progressiva de parcelas não certificadas por parcelas certificadas (Figura 4) que ilustra uma situação na qual a restituição gerada sobre a ortofoto identificou que havia apenas uma parcela (em amarelo). Conforme a base de dados repassada pela Prefeitura Municipal de Florianópolis-SC, haviam quatro parcelas ocupando a mesma localização, embora com discrepância posicional nos vértices de limite. Entretanto, quando a situação foi confrontada com os títulos de domínio, descobriu-se, a partir da verificação in loco, que a realidade era outra. Após o processo de agrimensura restaram três parcelas, cada uma correspondente a uma matrícula distinta. As coordenadas dos vértices de limite destas parcelas foram consideradas, então, certificadas e estas passaram a estar disponíveis tanto para atualizar a base de dados da prefeitura como para ir a registro. As demais parcelas não certificadas contíguas devem ter seus vértices ajustados a estes. 
Figura 4 - Exemplo de substituição de parcelas não certificadas (esq. em vermelho) por parcela certificada (dir. em verde).

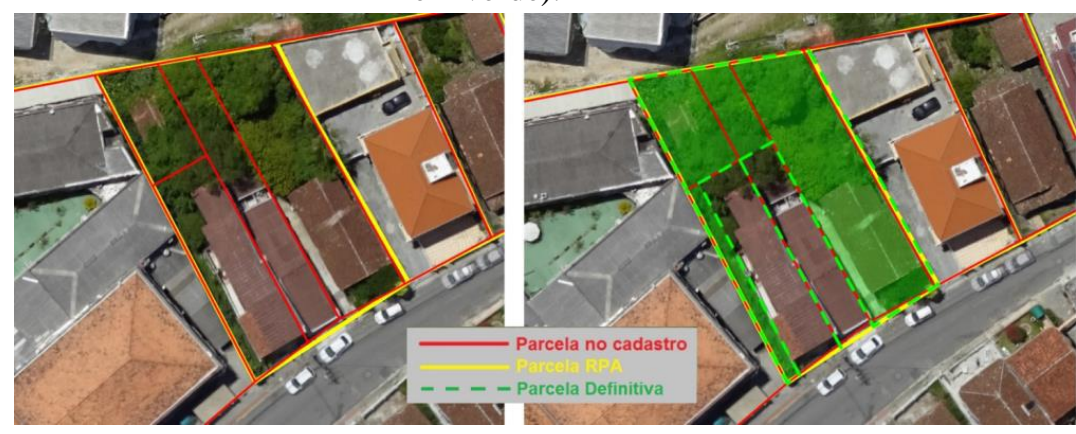

Fonte: França et al. (2018b).

Como apontado anteriormente, a base cadastral rural do INCRA é formada apenas por parcelas certificadas sucessivamente incrementadas, mas nada impede que venha a ser modelada uma integração com outras bases de dados (como a do Cadastro Ambiental Rural, por exemplo) de parcelas não certificadas, desde que sejam devidamente identificadas. Nas administrações municipais, um caminho natural é que as bases de dados cadastrais do território urbano sejam compostas inicialmente apenas por parcelas não certificadas, para ao longo do tempo irem cedendo espaço a parcelas certificadas através do mecanismo de atualização apontado no parágrafo anterior, de forma que ambos os tipos de parcela convivam de forma harmônica.

Ainda deve-se considerar que há parcelas não certificadas que assim permanecerão, seja pela sua própria natureza de não correspondência a título de domínio, seja pela não necessidade, seja pela não provocação/exigência ao ocupante/possuidor da parcela pelo órgão de gestão de cadastro ou do registro para a certificação. Isso em nada diminui a importância de que essas parcelas venham a ser modeladas já que cumprem importante papel para as funções arrecadatórias ou de planejamento e gestão territorial junto às administrações municipais.

Uma vez compreendido o conceito de parcela como a unidade cadastral, porção contínua do território, delimitada por vértices, definida em $2 \mathrm{D}$, certificada (com fins de ir a registro) ou não certificada, pode-se avançar para o conceito de Objeto Territorial. Conforme abordado no documento Cadastro 2014 da FIG (FIG, 1995; KAUFMANN; STEUDLER, 1998), parte da realidade territorial é modelada nos sistemas cadastrais na forma de parcelas; esta parte corresponde ao tecido ou estrutura fundiária básica. Outra parte da realidade territorial, entretanto, necessita de um conceito dotado de maior flexibilidade tanto pelo fato de existir fisicamente sem corresponder à parcela propriamente dita, como pelo fato de existir legalmente, mas igualmente não corresponder a uma parcela em si. Ademais, num caso como no outro, embora não sejam parcelas, estas ocorrências territoriais podem se dar acima ou abaixo da superfície, são importantes e devem ser consideradas na modelagem cadastral.

Para equacionar estas situações, a FIG propõe a figura dos Objetos Territoriais (OT) que para adequação à nossa proposta conceitual podem ser assim descritos:

Objeto Territorial é a uma porção do território em cujos limites ou localização condições homogêneas ocorrem.

Este é um conceito ainda mais abrangente que o de parcela, e assim o é para conseguir alcançar tudo que esteja relacionado à parcela sem corresponder fisicamente a esta, inclusive em outras dimensões além da 2D. Portanto, Objetos Territoriais são n-dimensionais.

Objeto Territorial é todo elemento natural, artificial ou existente por previsão legal sobre, ou sob a superfície topográfica, que goze de condições homogêneas em seus limites. Os Objetos Territoriais podem ser de dois tipos diferentes: legais ou físicos (KAUFMANN; STEUDLER, 1998; SANTOS et al., 2013).

Objeto Territorial Legal (OTL) é toda porção contínua que define um direito, uma responsabilidade ou uma restrição sobre o território de forma homogênea por legislação (conceito de RRR proposto pela FIG). O OTL não necessita estar delimitado em campo para existir. Enquadram-se como OTL as áreas de preservação permanente (APP), zoneamentos dos planos diretores municipais, reserva legal, servidão de passagem, entre outros. 
Objeto Territorial Físico (OTF) é todo elemento natural ou artificial fisicamente existente no território de forma homogênea ao longo de sua extensão, ou localização. Igualmente ao OTL, o OTF pode existir sobre ou sob a superfície. Enquadram-se como OTF as edificações em geral, vegetação, corpos d'água, linhas de transmissão, entre outros são exemplos (Figura 5) de objetos territoriais físicos e legais.

Figura 5 - Exemplos de Objetos Territoriais Físicos (esq.) e Legais (dir.).

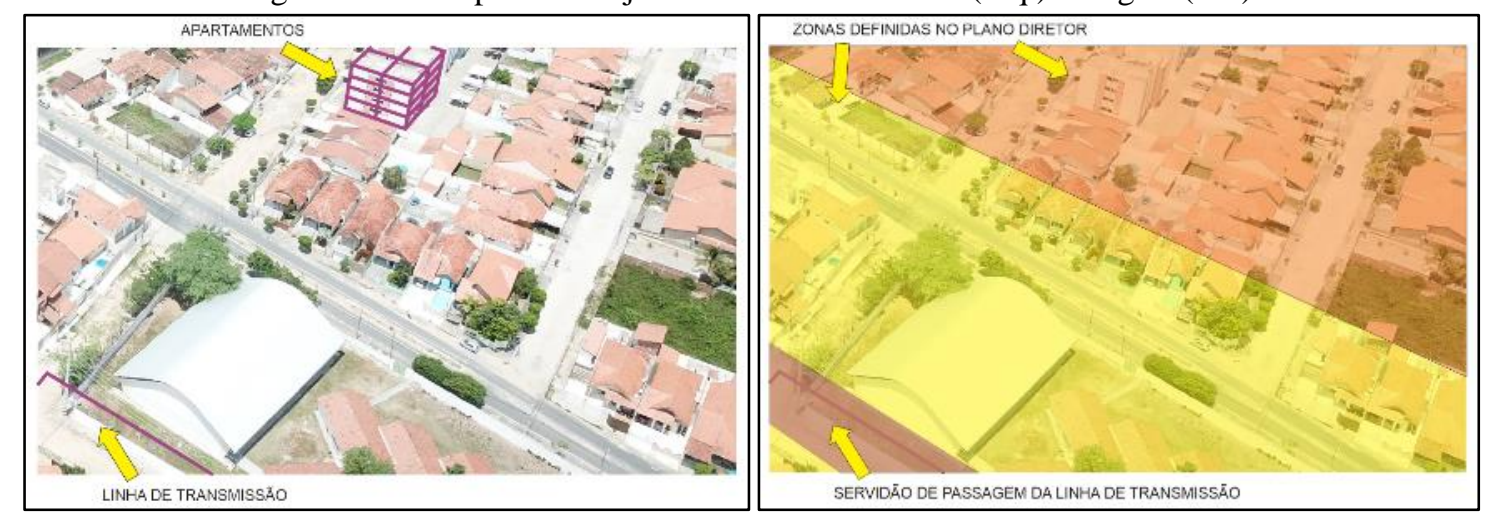

Fonte: Os autores (2020).

Esta diferenciação conceitual de Parcelas e Objetos Territoriais corresponde a um entendimento diverso daquele proposto nas Portaria 511/2009 do extinto Ministério das Cidades, intitulada Diretrizes para o Cadastro Territorial Multifinalitário (Brasil, 2009). Ali se propunha que cada tipo de restrição ou responsabilidade fosse modelada na forma de uma parcela. Desta maneira, entretanto, a complexidade de modelagem cadastral torna-se infinita e inadequada à nossa realidade na qual os parâmetros das normas e regras legais estão em constante modificação, além de muitas destas restrições legais não serem sequer georreferenciadas. Por exemplo, ao se diminuir ou aumentar um percentual de reserva legal sobre imóveis, ao se modificar a lei de uso e ocupação do solo, ao atualizar um plano diretor, mudança natural no curso de um rio, etc., todas as parcelas afetadas teriam que ser modificadas, algo que tornaria impossível a manutenção e atualização cadastral, bem como a conexão desta nova realidade com os títulos do registro.

Diferentemente, na conceituação presente dos autores, modificações de natureza legal como as citadas dizem respeito tão somente aos OTL afetados, mas as parcelas permanecem as mesmas (sendo elas certificadas ou não certificadas). A complexidade conceitual presente na portaria talvez explique em parte a não adesão às diretrizes propostas pelo Ministério das Cidades, muito embora grande esforço de divulgação e capacitação tenha sido feito junto às administrações municipais.

Destaca-se que os Objetos Territoriais, sejam legais ou físicos, podem se sobrepor entre si e sobrepor parcelas, mas sempre estarão vinculados a uma parcela territorial ou porção dela. Desta forma, a aplicação do conceito de Objetos Territoriais abre caminho para a modelagem cadastral $1 \mathrm{D}, 2 \mathrm{D}, 3 \mathrm{D}, \ldots, \mathrm{nD}$, permitindo incorporar outros elementos na gestão territorial além das parcelas e se tornando a fonte de inúmeros dos chamados cadastros temáticos multifinalitários (Capítulo 3, Premissa 5). Ainda, alguns Objetos Territoriais também terão ligação/correspondência com matrículas.

Cabe ressaltar, por fim, que ao definir as parcelas como sendo de natureza bidimensional e os OT como n-dimensionais não se propõe que necessariamente todo o Cadastro deva ser finalizado com parcelas 2D para se partir para a Objetos Territoriais 3D ou outra dimensão qualquer, já que ambos os conceitos (parcela e OT) se complementam e podem ser modelados e implementados paralelamente em um sistema cadastral. O que precisa ficar bem esclarecido é que, muito embora os métodos e técnicas de medição tenham evoluído rapidamente nas últimas décadas, incorporando a terceira dimensão nos levantamentos em massa cada vez com mais facilidade (fotogrametria digital, varredura a laser, etc.), o produto destas técnicas e métodos continua sendo o mesmo: modelos digitais de superfície, que estão mais próximos de OTF (feições do terreno) do que de parcelas (processos de agrimensura).

Tais observações objetivam apenas a uma definição de papeis e ao atendimento às premissas técnicas elencadas anteriormente com vistas à adequação à nossa realidade para viabilidade de um Cadastro para 0 Brasil. 


\section{REDE DE REFERÊNCIA E NORMAS DE LEVANTAMENTO}

Uma das premissas do Cadastro Territorial é a existência de uma Rede de Referência Cadastral para apoio aos levantamentos das parcelas (Capítulo 3, Premissa 2). Apesar desta premissa ser de conhecimento geral da academia e dos profissionais da área da mensuração, a forma de implantação e densificação da rede ainda não se consolidou e tampouco os critérios de ajustamento e métodos possíveis para este fim.

Blachut et al. (1979), afirma que para levantamentos cadastrais só são aceitáveis aqueles baseados em uma rede de referência monumentada, caso contrário, o sistema é técnica e economicamente inadequado.

Com a tecnologia de levantamento através de posicionamento por satélites (GNSS) e com as atuais soluções de correções em tempo real, entre outras, tornou-se mais rápida e produtiva a implantação de pontos de apoio aos levantamentos topográficos.

No entanto, quando se trata de levantamento de parcelas certificadas, com identificação de limites para fins cadastrais e consequentemente de registro de imóveis, com a demanda de poucos centímetros de precisão e nos quais se deve ter controle de qualidade através das tolerâncias permitidas entre vértices de uma parcela e suas lindeiras, a diferença de milímetros ou poucos centímetros nos pontos de apoio podem resultar em erros que não enquadrem o levantamento dentro das tolerâncias exigidas. Portanto, as normas técnicas devem avançar os conceitos e parâmetros de uma rede de referência.

Hasenack (2000) aponta como uma grande dificuldade em sua pesquisa, que teve como objetivo o estudo da documentação dos originais do Cadastro Territorial através de medições em campo, a falta de uma rede de referência.

Por todo território nacional é muito frequente a implantação de pontos para apoio aos levantamentos aerofotogramétricos, que geralmente não são aproveitados para outras finalidades, sobretudo por não existir regras e amparo legal para a manutenção de uma rede de referência municipal.

A rede de referência não se trata de apenas um conjunto de pontos georreferenciados "espalhados" pelo município. Critérios devem ser definidos em normas técnicas exequíveis, econômicas, simples, tecnicamente seguras e sustentáveis. A NBR14166 em vigor, que trata dos procedimentos para a Rede de Referência Cadastral Municipal (RRCM), não contempla as necessidades para a implantação da rede considerando tais critérios, pois desde o fim da década de 1990 não foi atualizada encontrando-se obsoleta e ineficiente.

Detalhamento do ajustamento de observações, especificação de métodos de medições terrestres e uso de posicionamento por satélite, somados à precisão posicional dos vértices da rede, são algumas das principais perguntas que a atual norma não responde.

Como contribuição, esse artigo traz algumas reflexões e propostas para alcançar a Premissa 2, existência da Rede de Referência.

\subsection{Implantação e Densificação}

O arranjo da rede de referência deve ser composto basicamente por dois processos: um de implantação e um de densificação.

O processo de implantação é o estágio inicial da rede. Neste caso, o município deve planejar uma área abrangente para a instalação de marcos e as medições devem estar diretamente vinculadas ao Sistema Geodésico Brasileiro, ou seja, em sua totalidade as coordenadas dos vértices deste estágio são determinadas a partir de técnicas de posicionamento por satélite GNSS. Para os vértices de implantação dar-se-á o nome de Vértices Superiores (VS) da rede de referência.

Para os VS deverá ser realizado um planejamento considerando o ajustamento de observações sobre os vetores formados entre os vértices da rede de referência e o SGB, e quando possível considerar os vetores para ajustamento em relação aos VS vizinhos.

Uma vez implantados os VS dar-se-á início ao segundo processo: o de densificação. Este processo deve ser realizado ao longo do tempo e esta etapa deve ser em dois níveis. O primeiro quando um novo vértice passa a ser inserido na rede com medições considerando ao menos dois VS ou VS e SGB como referência, nesse caso a proposta de nomenclatura é de Vértice Principal (VP). 
As medições de VP podem ser tanto via posicionamento por satélite como medições terrestres com uso de Estação Total, desde que sejam utilizados métodos que atendam a necessidade de ajustamento.

Ao densificar a rede chegará o momento em que os VS e SGB estarão distantes e não serão mais considerados pontos vizinhos para garantir a homogeneidade na rede em uma determinada parte do território municipal. Para esses casos a proposta é que se tenha a densificação em um segundo nível, o dos Vértices de Apoio (VA). Os VAs podem ter seu ajustamento com base em ao menos dois VP, VP combinado com VS, VP combinado com SGB, ou seja, sempre terá um VP no ajustamento. Além disso, existirá a necessidade de se densificar a rede ao ponto de que um VA terá como referência outros VAs pela proximidade dos vértices.

Para facilitar a compreensão, o Quadro1 mostra um resumo desta proposta, apresentando as referências para cada tipo de vértice, nome, sigla e técnicas de medição. Um esquema de estruturação e apoio dos níveis da rede também é demonstrado (Figura 6).

Quadro 1 - Tipos de vértices da RRCM.

\begin{tabular}{|c|c|c|c|}
\hline Nome do Vértice & Sigla & Referências & Técnicas \\
\hline Vértice Superior & VS & Pelo menos dois vértices SGB & GNSS \\
\hline Vértice Principal & VP & $\begin{array}{l}\text { a) Pelo menos dois VS } \\
\text { b) } \mathrm{SGB}+\mathrm{VS}\end{array}$ & GNSS e Estação Total \\
\hline Vértice de Apoio & VA & $\begin{array}{l}\text { a) Pelo menos dois VP } \\
\text { b) VP+VS } \\
\text { c) VP+VA } \\
\text { d) VP+SBG } \\
\text { e) VA+SGB } \\
\text { f) VA+VA }\end{array}$ & GNSS e Estação Total \\
\hline
\end{tabular}

Fonte: Os autores (2020).

Figura 6 - Esquema proposto para a hierarquia de rede de referência.

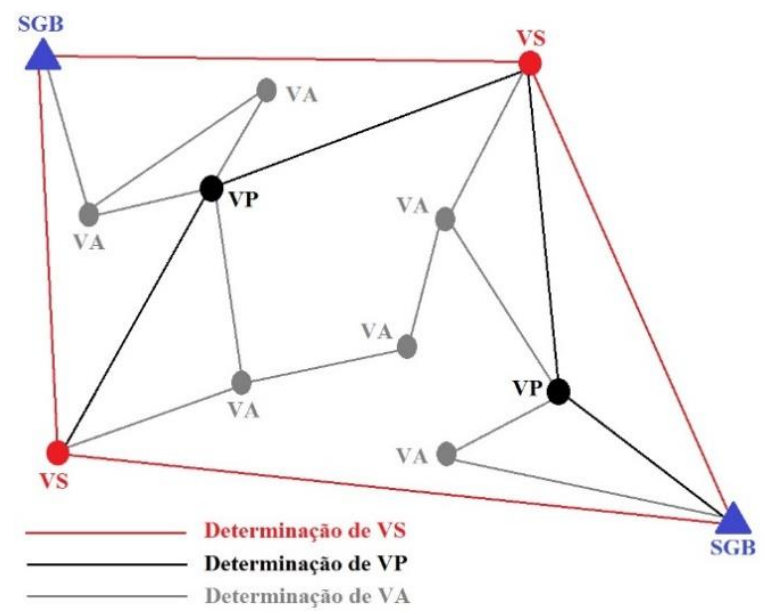

Fonte: Os autores (2020).

Em todos os casos apresentados na Tabela 1 deve-se considerar o princípio da vizinhança, fazendo com que os novos vértices sejam densificados pelos vértices mais próximos, tornado as regiões da rede de referência homogêneas.

Esta proposta apresenta uma hierarquia no âmbito do planejamento e não relativa aos valores de precisão do ponto ou classificado por ordem. Ainda, simplifica a rede para apenas três níveis ao invés dos doze níveis atuais na NBR14166/1998 (item 4.2) (ABNT, 1998).

\subsection{Precisão Posicional}

A precisão posicional esperada para os vértices da rede de referência determina uma série de 
procedimentos que devem ser tomados. Tal precisão deve estar relacionada com a finalidade a que se destinam os levantamentos que nela se apoiam.

Considerando a parcela como o principal objeto do levantamento cadastral, o valor de precisão posicional de oito centímetros para os seus vértices vêm sendo aceito academicamente e até mesmo legalmente (Capítulo 3, Premissa 9). Luz (2013) apresentou um estudo considerando o conceito de precisão e tolerância e chegou na proposta de oito centímetros na planimetria, o qual os autores consideram seguro e tecnicamente viável. Este valor aparece também no Decreto 9.310/2018 (BRASIL, 2018) que regulamenta a lei do REURB, muito embora haja ali um equívoco de texto (na redação do decreto e subsequente revisão) ou de conceito (ao confundir parcelas 2D com objetos territoriais $3 \mathrm{D}$ ), pois foram considerados vértices tridimensionais com valor de precisão esférica (tridimensional).

Coelho e Chaves (2005) realizaram um estudo para determinação de precisão para os vértices de imóveis urbanos considerando propagação de precisões para poligonação eletrônica e pontos irradiados. Os autores concluíram que é possível alcançar precisão melhor do que dez centímetros para um ponto irradiado a uma distância de até cem metros partindo de um vértice da rede de referência com cinco centímetros de precisão. Fazendo uma analogia a esse estudo, o ponto irradiado pode ser o vértice da parcela.

Considerando as propagações das precisões desde os vértices do SGB, sobretudo quando se utiliza de métodos de levantamento por topografia clássica, fica impossível atingir precisão milimétrica. Vetores longos com distância de dezenas ou centenas de quilômetros de linha base geram precisões de poucos centímetros para os novos pontos. Ajustamento por poligonais e estação livre quando utilizado na densificação da rede também entram na casa centimétrica de precisão. Klein et al. (2017) apresenta resultados do uso do método de Estação Livre para densificação de rede e os valores de precisão apresentados na pesquisa variaram de 4 a 37 $\mathrm{mm}$. Sendo assim, torna-se impossível a rede de referência ter precisão milimétrica.

A proposta deste trabalho considerando os estudos realizados pelos autores acima citados e visando resultados reais de precisão posicional para os vértices da rede de referência, recomenda a adoção do valor de $5 \mathrm{~cm}$ na planimetria da RRCM.

\subsection{Manutenção e Gestão da RRCM}

A municipalidade deve se estruturar de forma que seja possível contar com o trabalho dos profissionais que atuam diariamente com a mensuração de parcelas e imóveis (Capítulo 3, Premissa 7). O processo inicial de implantação da rede de referência deve ser de responsabilidade do município. No entanto, dispor de equipe para densificar a rede pode ser um gasto oneroso e, por vezes, sem necessidade.

Se sob responsabilidade da administração municipal forem implantados os VSs e, ao mesmo tempo forem determinadas as regras através de manual técnico para a densificação da rede de referência (com procedimentos padronizados, métodos de levantamento, orientação para ajustamento e produto a ser gerado pelos técnicos e engenheiros, tais como relatórios técnicos, arquivos brutos e demais dados necessários para manter a estrutura organizacional da rede), a municipalidade passará a contar com a parceria de trabalhos de mensuração que diariamente são realizados por diversos profissionais, os quais operam atualmente de forma não padronizada para satisfazer uma necessidade pontual de contrato com variadas finalidades.

Neste caso, a municipalidade necessitaria de um corpo técnico mais enxuto para analisar os dados enviados pelos profissionais a fim de se homologar novos vértices da rede de referência, e os profissionais passam a ser parceiros na densificação da mesma.

Em um primeiro momento essa posposta pode parecer não adequada, mas o fato é que desde 1998, quando publicada a NBR14166, até os dias atuais é praticamente inexistente um exemplo de funcionamento de uma RRCM no Brasil. Faz-se necessário, portanto, buscar ideias inovadoras uma vez que a tecnologia e a compreensão das necessidades cadastrais avançaram desde então. Com essa proposta, a gestão da rede de referência continua sendo municipal, mas com a participação de toda classe profissional da área da mensuração. 


\section{ARRANJO DO SISTEMA}

A dificuldade em consolidar um Cadastro Territorial sólido e eficiente no Brasil se dá, em parte, pela legislação territorial existente que não define uma estruturação organizacional e nem define de forma objetiva o fluxo de processos, cabendo às várias entidades envolvidas a definição isolada, meramente atendendo sua necessidade e a legislação.

O item mais oneroso do Cadastro Territorial é o levantamento de campo, o qual objetiva a determinação das coordenadas dos vértices dos limites das parcelas. Este item deve ser custeado pelo real interessado no imóvel, que é seu proprietário, assim como acontece com o Registro de Imóveis. Este princípio já é adotado para o georreferenciamento de imóveis rurais, que está compondo todo o cadastro territorial na área rural.

As parcelas do cadastro territorial rural, conforme delineado pelos artigos da Lei 10.267/2001, estão sendo incorporadas à base de dados do INCRA através de prazos estabelecidos por classes de imóveis rurais conforme a sua área (Decretos Federais $n^{\circ} 4.449 / 2002, n^{\circ} 5.570 / 2005, n^{\circ} 7.620 / 2011$ e $n^{\circ} 9.211 / 2018$ ) e conforme haja movimentação de processos a interesse dos proprietários nos registros de imóveis. Ou seja, o Instituto Nacional de Colonização e Reforma Agrária - INCRA, que é o órgão gestor desse cadastro, iniciou a sua base cadastral do zero que está sendo incrementada progressivamente conforme novas parcelas são apresentadas e submetidas ao processo de certificação.

Porém, da forma que o cadastro territorial rural está sendo composto (progressivamente incrementado apenas por parcelas certificadas), não é viável para a área urbana por questões temporais, visto que a quantidade de imóveis urbanos é imensamente mais numerosa e o retardo na composição do Cadastro Territorial, não permitiria a cobrança dos impostos sobre a propriedade desconhecida até a completude do cadastro.

Faz-se necessária uma estrutura pública mínima para permitir o funcionamento do Cadastro Territorial autossustentável, cumprindo sua gestão e definindo regras claras para que os dados sejam recebidos de forma estruturada a fim de manter sua atualização ao dia. O Cadastro Territorial, diferentemente do cadastro multifinalitário, perde sua eficiência se for atualizado aos saltos, a uma determinada época.

Portanto, há de se definir uma sistemática a ser adotada pelo poder público para que o Cadastro Territorial funcione num fluxo de processos sustentáveis. Tal fluxo foi proposto por França et al. (2018) que destaca (Figura 7) que a implantação pode se dar a partir de uma base cartográfica existente, ou criada especificamente para este fim por processos de sensoriamento remoto, como a aerofotogrametria. Em ambos os casos, geram-se as parcelas não certificadas, cuja geometria não foi confirmada com o levantamento em campo, bem como seus vértices ainda não foram materializados.

Figura 7 - Fluxo para implantação do Cadastro Territorial.

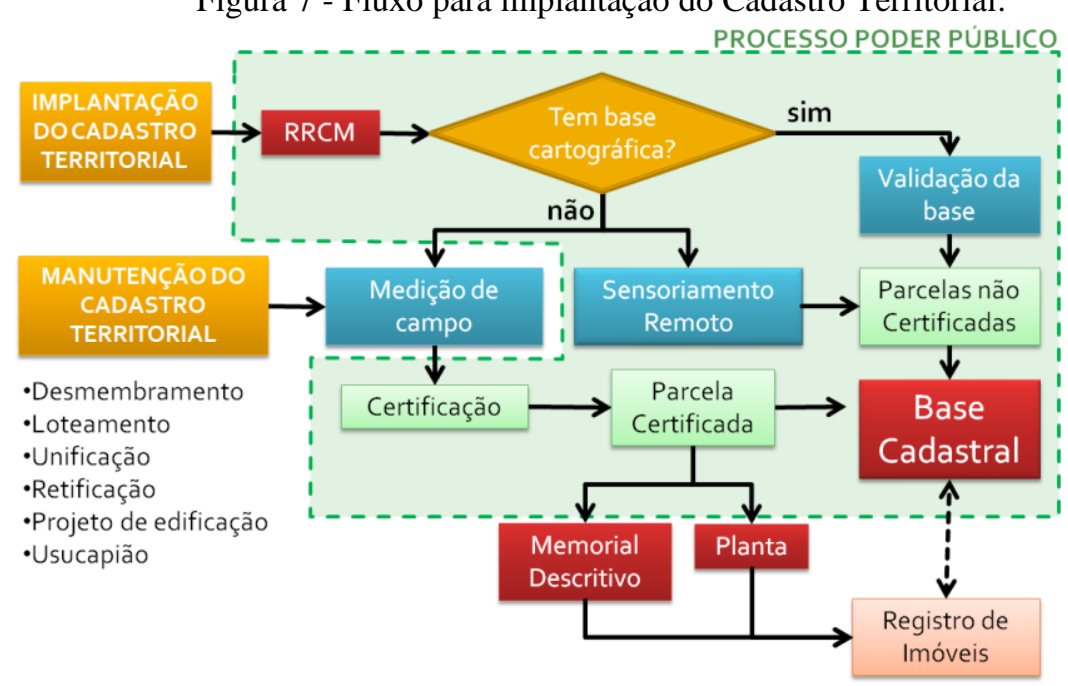

Fonte: Adaptada de França et al. (2018).

Este fluxo exige do poder público uma estrutura mínima de funcionamento para a gestão do Cadastro Territorial, implantando inicialmente uma Rede de Referência Cadastral Municipal (RRCM), criando as parcelas não certificadas e realizando a manutenção das parcelas que compõem a base cadastral. Porém, 
durante o fluxo de manutenção do Cadastro Territorial, a parte onerosa (levantamento de campo) é custeada pelo proprietário (principal interessado) quando de fato ele necessitar. Para França et al. (2018) a manutenção da base cadastral deve ser realizada obrigatoriamente a partir de uma medição de campo com topografia e, somente por esta via, a parcela provisória é devidamente certificada passando a situação de definitiva.

Segundo França et al. (2018) A manutenção da base cadastral surge a partir do interesse do proprietário, como consequência de desmembramento, unificação, loteamento, retificação, usucapião e qualquer outra ação que exija mudança ou alteração na parcela. Além destas, a aprovação de um projeto de edificação em determinada parcela também poderá ativar a necessidade de manutenção da base cadastral, visto que nestes casos também já é comumente realizado um levantamento topográfico.

O mecanismo de certificação criado pela Lei 10.267/2001 é mais uma boa prática que deve ser aproveitada da experiência do cadastro territorial rural e estendido para o Cadastro Territorial no Brasil como um todo (rural e urbano). As fragilidades do sistema registral são conhecidas e o processo de certificação criado para os imóveis rurais, embora imperfeito, corresponde a um grande avanço em termos de garantia legal. A certificação de uma parcela rural corresponde a afirmação do órgão de cadastro territorial (o INCRA, no caso) de que uma dada parcela submetida por um profissional responsável credenciado à análise não se sobrepõe a outra parcela anteriormente certificada. Sendo contíguas, duas parcelas certificadas devem dividir os mesmos vértices do limite comum, o que força uma segunda determinação (ou aceitação) dos vértices comuns e consequente corresponsabilidade técnica pelas coordenadas determinadas. Ao final do processo, não havendo sobreposição, a parcela é declarada como certificada e são as suas coordenadas definidoras de limite que podem ir a registro, sendo gravadas em uma matrícula (BRASIL, 2013b).

Em relação a parcelas provisórias lindeiras, a análise deve ser quanto à geometria e quanto às confrontações. Quanto à geometria, a comparação não será entre vértices, mas da sobreposição ou vazios entre as parcelas, pois nem sempre a quantidade de vértices será a mesma entre a parcela fruto do levantamento topográfico de campo e a(s) parcela(s) provisória(s) lindeira(s).

Se a tolerância estabelecida na comparação for atendida, o órgão gestor do cadastro deve ajustar os vértices das parcelas provisórias para os vértices da parcela definitiva que foi certificada, a figura 7 mostra um esquema de atualização da base cadastral com a parcela certificada.

Figura 8 - Exemplo de atualização cadastral de parcela certificada.
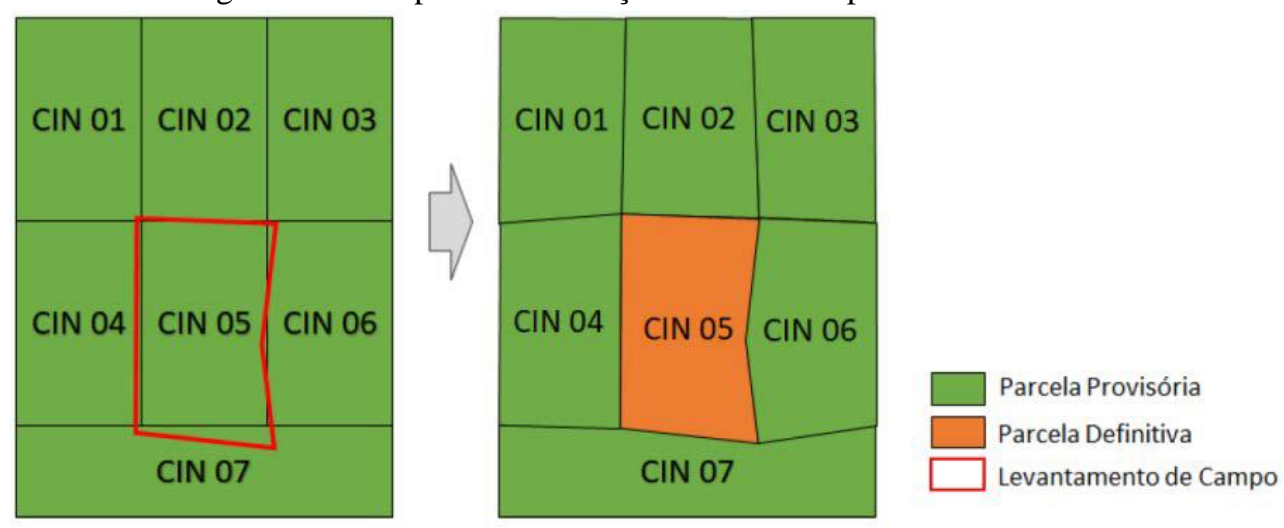

Fonte: França et.al. (2018).

Se o posicionamento entre a parcela a ser certificada e as parcelas provisórias lindeiras estiver fora da tolerância, o profissional deverá iniciar um processo administrativo junto ao órgão gestor do cadastro para os ajustes necessários das parcelas provisórias, sendo o órgão gestor responsável pelo ajuste geométrico da base cadastral. Somente após o ajuste, a parcela medida em campo poderá ser certificada.

Na manutenção do Cadastro Territorial, resta ao poder público analisar a certificação das parcelas medidas em campo e atualizar a base cadastral. Usando como referência o Sistema de Gestão Fundiária (SIGEF) adotado pelo INCRA no Georreferenciamento de Imóveis Rurais, a gestão de Cadastro Territorial pode ser automatizada, atendendo a quase totalidade das certificações sem dependência de um profissional que onera o poder público, e que na maioria das vezes não existe no quadro funcional das prefeituras. 


\section{DESAFIOS E PERSPECTIVAS}

A implantação de um sistema cadastral territorial é o maior desafio a ser enfrentado por profissionais e gestores responsáveis pelas políticas de gestão do território, pois envolve a elaboração de uma legislação para dar segurança jurídica ao sistema, a produção de normas técnicas aplicáveis ao modelo, formação de profissionais para atuarem na gestão, na execução e na manutenção do Cadastro.

Três grandes obstáculos são reconhecidos como inibidores na implantação de sistemas cadastrais eficientes e permanecem atuais, constituindo-se como desafios a serem enfrentados segundo Brandão et al. (2010): a capacitação profissional, o desconhecimento tecnológico e de procedimentos, e a falta de cooperação entre esferas de governo e administrações prejudicando o intercâmbio de dados e informações.

Os dois primeiros aspectos apontados - capacitação profissional e desconhecimento tecnológico e de processos - alcançam tanto a formação dos futuros profissionais que atuarão no Cadastro quanto os que atualmente já estão alocados nos respectivos setores cadastrais das prefeituras municipais. Aqui incluem-se os diferentes níveis de ensino (formação continuada, técnico, tecnológico, graduação e pós-graduação) de áreas ligadas, de forma ampla, à gestão territorial, tais como: agrimensura, cartografia, geoprocessamento, geografia, engenharia, arquitetura, administração, direito, dentre outras, e passa por aspectos de uniformização terminológica e conceitual do Cadastro, atualização e harmonização das matrizes curriculares e maior interligação entre teoria e prática. A título de exemplo, Leipelt et al. (2017) apresenta um estudo comparativo de cursos superiores de engenharia cartográfica e de agrimensura no Brasil, o qual aponta para um desequilíbrio entre os respectivos currículos. $\mathrm{O}$ estudo dos referidos autores indica que conteúdos sobre Cadastro são ministrados nas instituições pesquisadas com cargas horárias entre 45 e 136 horas-aula, o que evidencia uma forte diferença formativa entre os egressos de cursos superiores nessa área, que serão os futuros profissionais a atuar na área cadastral. No que tange à capacitação profissional de servidores públicos atualmente ligados aos setores de Cadastro nas prefeituras municipais, desde a extinção do Ministério das Cidades em 2018 não há relatos de novos cursos ou programas sobre Cadastro em larga escala.

A falta de cooperação entre esferas de governo e administrações (extra e intraorganizacional) complementa o quadro de desafios e é manifestamente um dos maiores desafios à implantação de um modelo de Cadastro Territorial. Neste sentido, há uma lacuna do que se poderia chamar de "cultura cadastral" tanto de nossa sociedade quanto das organizações, que seria uma compreensão comum e disseminada, porém suficiente, da estrutura elementar e dos benefícios e vantagens do Cadastro Territorial.

Outro aspecto que pode ser apontado como um desafio é o entendimento que o Cadastro Territorial elaborado conforme a proposta aqui apresentada é a base de todos os demais Cadastros e Sistemas de Informação sobre o Território, garantindo qualidade legal e geométrica, ou seja, é também o ponto de partida para a multifinalidade cadastral.

Em termo das pesquisas diretamente relacionadas à implantação do Cadastro Territorial, os principais temas futuros devem abordar os aspectos técnicos referentes às precisões e propagação de variâncias das medições, integração de métodos de levantamentos, programas adequados a cada fase do processo, correlação entre os vários sistemas, interoperabilidade de dados, infraestrutura de dados espaciais para o cadastro, formas de acesso de dados pelo público e profissionais envolvidos, normativas e legislação cadastral. Dentre os temas apontados, um desafiador e de grande interesse seria o desenvolvimento de um protótipo de sistema para certificação de parcelas em meio urbano, que pudesse ser elaborado em plataforma aberta e disponibilizado às administrações municipais.

Sem a pretensão de esgotar o assunto, resta ainda um conjunto de questões a serem respondidas nos próximos anos: a) quando teremos implantado um Cadastro Territorial de tal forma que todas as parcelas estejam devidamente identificadas e medidas possibilitando restituir a qualquer momento seus limites? b) quando teremos os direitos de propriedade garantidos tendo como suporte geométrico o Cadastro e ações como as de regularização fundiária fiquem apenas nos anais da História? c) quando cada cidadão terá acesso às informações territoriais de seu imóvel de forma rápida e confiável? d) quando os profissionais da área de medição terão um padrão de levantamento adotado nacionalmente? Espera-se ter as respostas o mais breve possível com a participação de todos os envolvidos no processo colaborando com a proposta aqui apresentada. 


\section{CONSIDERAÇÕES FINAIS}

O Cadastro Territorial através da base cadastral parcelar, assim como o mapeamento dos objetos territoriais, integrado ao Registro de Imóveis, são condicionantes obrigatórias para o adequado ordenamento territorial.

Uma parte dos municípios brasileiros já possui sistemas de informações geográficas com mapeamento do território gerindo a cartografia cadastral de alta qualidade posicional e de detalhes obtida por sensoriamento remoto. Os procedimentos elencados neste artigo visam manter esses produtos como forma de aquisição das parcelas não certificadas, que ao longo do tempo passam a ser certificadas com as medições em campo. Esse processo em um primeiro momento pode não ser agradável considerando a questão temporal quando se estimam décadas para um avanço da base cadastral com parcelas certificadas, mas se mostra viável, pois conta com toda a estrutura de profissionais e interessados (requerentes de processos de medições) de forma que o processo não onere economicamente os municípios. Nenhuma prefeitura de cidades com médio ou grande porte conseguiria medir em campo todas as parcelas, essa tarefa deve acontecer sob demanda e ao longo do tempo.

O fluxo de implantação e manutenção do Cadastro Territorial apresentado neste trabalho demonstra a possibilidade de se integrar os serviços de medições para diversas finalidades que envolvem a mensuração de imóveis em um município de qualquer porte e em qualquer estágio de maturidade cadastral ou tecnológica. Desta forma, a proposta atinge o objetivo de atualização cadastral diária e não a periodicamente entre contratos de aerolevantamentos. Os serviços de sensoriamento remoto podem e devem continuar, sobretudo por gerarem conhecimento amplo do território, além do mapeamento das parcelas não certificadas.

A escolha da técnica de levantamento cadastral é uma decisão crítica para técnicos e para os administradores municipais. A relação entre os avanços tecnológicos para a produção de informação e os procedimentos de gestão não evoluem em um mesmo ritmo. Enquanto se observa uma rápida evolução no uso de novas tecnologias de aquisição e processamento de dados geográficos e cadastrais, os avanços nos processos de gestão são bem menos dinâmicos. Para que o fluxo proposto funcione os processos de gestão precisam estar consolidados em uma prefeitura.

Por fim, conclui-se que medidas como as propostas neste artigo auxiliam a de fato dar início ao Cadastro Territorial preconizado pela FIG e semelhante aos observados em países com mais tradição nesta área. O Brasil com sua extensão territorial e quantidade de municípios possui particularidades que não permitem a simples cópia de um sistema europeu, por exemplo. Entretanto, com o fluxo do processo organizado e apoiado a normas técnicas o Cadastro pode, de fato, acontecer no Brasil.

\section{Contribuição dos Autores}

Todos os autores participaram das etapas de conceptualização, metodologia, redação, revisão e edição deste artigo.

\section{Conflitos de Interesse}

Os autores declaram que não há conflito de interesses relacionados à confecção do manuscrito.

\section{Referências}

ARAÚJO, A.L.; BOSCATTO, F.; BRAGHIROLLI, G.; FRANÇA, R.M. de. Fragilidades do SIGEF e da $3^{\text {a }}$ Edição da NTGIR: Lições de Cadastro para o SINTER. In: SIMPÓSIO BRASILEIRO DE CIÊNCIAS GEODÉSICAS E TECNOLOGIAS DA GEOINFORMAÇÃO, VII., 2018, Recife, Anais... Recife: UFPe, $2018 . \quad$ Disponível em: <https://www.ufpe.br/documents/39451/1384233/Anais+do+VII+SIMGEO/2ff23c73-935d-4418-8728fefb24630f34>. Acesso em: 28 jun.2020. 
ASSOCIAÇÃO BRASILEIRA DE NORMAS TÉCNICAS (ABNT). ABNT NBR 14.166: Rede de Referência Cadastral Municipal - Procedimentos. Rio de Janeiro: ABNT, 1998.

BLACHUT, T. J., CHRZANOWSKI, A., SAASTAMOINEN, J.H. Cartografia y levantamientos urbanos. Dirección General de Geografia dei Territorio Nacional. New York: inc. Springer-Verlag. 1979.

BRANDÃO, A. C. O Princípio da Vizinhança Geodésica no Levantamento Cadastral de Parcelas Territoriais. 2003. 129p. Tese (Doutorado em Engenharia de Produção) - Programa de Pós-Graduação em Engenharia de Produção, Universidade Federal de Santa Catarina. Florianópolis, 2003.

BRANDÃO, A. C.; CARNEIRO, A. F. T.; PHILIPS, J. W. . Atualidades, desafios e perspectivas do Cadastro no Brasil. In: 1er Congreso Internacional de Catastro Unificado y Multipropósito. 2010, Jaén, Espanha, Anais... Jaén: Universidad de Jaén. Disponível em: <http://coello.ujaen.es/congresos/cicum/ponencias/Cicum2010.3.12_Brandao_y_otros_Atualidades_desa fios_e_perspectivas_do_cadastro_no_brasil.pdf >. Acesso em: 11 nov. 2020.

BRASIL. Constituição (1988). Constituição: República Federativa do Brasil. Brasília, DF: Presidência da República, 2020 Disponível em: 〈http://www.planalto.gov.br/ccivil_03/constituicao/constituicao.htm〉. Acesso em: 16 jun 2020.

Decreto $\mathbf{N}^{\mathbf{0}}$ 9.310, de 15 de março de 2018. Institui as normas gerais e os procedimentos aplicáveis à Regularização Fundiária Urbana e estabelece os procedimentos para a avaliação e a alienação dos imóveis da União. Brasília, DF: Presidência da República, [2018].. Disponível em: <http://www.planalto.gov.br/ccivil_03/_ato2015-2018/2018/decreto/d9310.htm>. Acesso em: 17 jun 2020.

Lei Federal $\mathbf{N}^{\circ}$ 6.015, de 31 de dezembro de 1973. Dispõe sobre os registros públicos e dá outras providências. Brasília, DF: Presidência da República, [2000]. Disponível em: <http://www.planalto.gov.br/ccivil_03/leis/16015compilada.htm>. Acesso em: 17 jun 2020.

Lei Federal $\mathbf{N}^{\mathbf{0}} \mathbf{1 0 . 2 6 7}$, de 28 de agosto de 2001. Altera dispositivos das Leis nos 4.947, de 6 de abril de 1966, 5.868, de 12 de dezembro de 1972, 6.015, de 31 de dezembro de 1973, 6.739, de 5 de dezembro de 1979, 9.393, de 19 de dezembro de 1996, e dá outras providências. Brasília, DF: Presidência da República, [2001]. Disponível em: <http://www.planalto.gov.br/ccivil_03/leis/leis_2001/10267.htm>. Acesso em: 20 jun 2020.

Ministério das Cidades. Portaria $\mathbf{N}^{\mathbf{0}}$ 511, de 7 de dezembro de 2009. Diretrizes para a criação, instituição e atualização do Cadastro Territorial Multifinalitário (CTM) nos municípios brasileiros. Brasília, DF: Ministério das Cidades, [2009]. Disponível em: <https://www.normasbrasil.com.br/norma/portaria-511-2009_217279.html>. Acesso em: 20 jun 2020

COELHO, L. A. N. ;CHAVES, J. C.. Precisão na determinação das coordenadas dos vértices de imóveis urbanos. Revista Brasileira de Cartografia, v. 67, n. 2, p. 287-305, mar/abr. 2015. Disponível em: <http://www.seer.ufu.br/index.php/revistabrasileiracartografia/article/view/44662>. Acesso em: 25 jun.2020.

INTERNATIONAL FEDERATION OF SURVEYORS (FIG). Statement on the Cadastre. FIG Publication. Canberra, n.11, 1995. Disponível em: 〈https://fig.net/resources/publications/figpub/pub11/figpub11.asp〉. Acesso em: 23 jun.2020.

Fit-For-Purpose Land Administration. FIG Publication. Copenhagen, n.60, 2015. Disponível em: 〈https://www.fig.net/resources/publications/figpub/pub60/Figpub60.pdf>. Acesso em: 23 jun.2020.

FRANÇA, R. M. de; ARAÚJO, A.L.; BOSCATTO, F.; CABRAL, C.R.; COLLISCHONN, C. Parcelas e Objetos Territoriais: Uma Proposta para o SINTER. In: CONGRESSO BRASILEIRO DE CADASTRO TÉCNICO MULTIFINALITÁRIO E GESTÃO TERRITORIAL, 13. 2018, Florianópolis. Anais... Florianópolis, UFSC, 2018. Disponível em: <http://ocs.cobrac.ufsc.br/index.php/cobrac/cobrac2018/paper/view/492/243>. Acesso em: 23 jun.2020.

FRANÇA, R.M. de; ARAÚJO, A.L.; BOSCATTO, F. Uso de RPAs para Definição de Parcelas Provisórias do Cadastro Territorial. In: SIMPÓSIO BRASILEIRO DE CIÊNCIAS GEODÉSICAS E 
TECNOLOGIAS DA GEOINFORMAÇÃO, VII., 2018, Recife, Anais.. Recife: UFPe, 2018. Disponível em: <https://www.ufpe.br/documents/39451/1384233/Anais+do+VII+SIMGEO/2ff23c73-935d-44188728-fefb24630f34>. Acesso em: 28 jun.2020.

HASENACK, M. A cartografia cadastral no Brasil. 2013. 201p. Tese (Doutorado em Engenharia Civil) Programa de Pós-Graduação em Engenharia Civil, Universidade Federal de Santa Catarina, Florianópolis, 2013.

HASENACK, M. Originais do levantamento topográfico cadastral possibilidade de sua utilização para a garantia dos limites geométricos dos bens imóveis. 2000. 161p. Dissertação (Mestrado em Engenharia Civil) - Programa de Pós-Graduação em Engenharia Civil, Universidade Federal de Santa Catarina Florianópolis, 2000.

INSTITUTO NACIONAL DE COLONIZAÇÃO E REFORMA AGRÁRIA (INCRA). Manual Técnico de Limites e Confrontações: Georreferenciamento de Imóveis Rurais. [Brasília:INCRA], 2013a. Disponível em: <https://www.colegioregistralrs.org.br/wp-content/uploads/2013/10/Manual.pdf> . Acesso em: 20 jun 2020.

INSTITUTO NACIONAL DE COLONIZAÇÃO E REFORMA AGRÁRIA (INCRA). Manual Técnico de Posicionamento: Georreferenciamento de Imóveis Rurais. [Brasília: INCRA], 2013b. Disponível em: <https://metrica.zendesk.com/hc/pt-br/articles/203840955-Manual-T\%C3\%A9cnico-de-Posicionamento1\%C2\%AA-Edi\%C3\%A7\%C3\%A3o-da-NTGIR-INCRA>. Acesso em: 20 jun 2020.

KAUFMANN, J.; STEUDLER, D. Cadastre 2014: A vision for a future cadastral system. FIG Publication. Rüdlingen, $1998 . \quad$ Disponível em: <https://www.fig.net/resources/publications/figpub/cadastre2014/translation/c2014-english.pdf>. Acesso em: 23 jun.2020.

KLEIN, I.; GUZATTO, M. P. ; HASENACK, M. ; CABRAL, C. R. ; LIMA, A. P. B. ; FRITSCHE, S. ; REGINA JUNIOR, L. A. M. ; MOMO, G. F. . Rede de referência municipal para estações livres: Uma proposta de baixo custo e grande abrangência. Revista Brasileira de Cartografia, v. 69, p. 519-532, 2017. Disponível em: <http://www.seer.ufu.br/index.php/revistabrasileiracartografia/article/view/44346>. Acesso em: 26 jun.2020.

LEIPELT, D.; ROCHA, R.; NIEVINSKI, F. . Análise preliminar comparativa dos currículos de Eng. Cartográfica e Eng. de Agrimensura no Brasil. In: IV SIMPÓSIO BRASILEIRO DE GEOMÁTICA. 2017, Presidente Prudente, Anais... Presidente Prudente: UNESP, 2017. Disponível em: <http://docs.fct.unesp.br/departamentos/cartografia/eventos/2017_IV_SBG/_artigos/2017_SBG_CTIG_p aper_76.pdf>. Acesso em 11 nov. 2020.

LUZ, L. A. da S. Uma proposta para a precisão posicional no cadastro urbano brasileiro. 2013. Dissertação (Mestrado em Engenharia Civil) - Programa de Pós-Graduação em Engenharia Civil, Universidade Federal de Santa Catarina Florianópolis, 2013.

MELO, M. Breves anotações sobre o Registro de Imóveis. Boletim do IRIB em Revista , v. 327, p. 32-49, 2006. Disponível em: <https://www.yumpu.com/pt/document/view/12889177/breves-anotacoes-sobre-oregistro-de-imoveis-educartorioorgbr $>$. Acesso em 30 jun 2020.

ORGANIZAÇÃO DAS NAÇÕES UNIDAS (ONU). Fit-For-Purpose Land Administration: Guiding Principles for Country Implementation. ONU: Nairobi, 2014. 132p. Disponível em: <https://www.fig.net/news/news_2016/2016_07_gltnguide/fit-for-purpose-land-adm-guiding-principlesfor-country-implementation.pdf $>$. Acesso em: 23 jun.2020

PHILIPS, J. Breve histórico do cadastro de imóveis no mundo. Revista de direito imobiliário/IRIB, São Paulo: RT, n. 317, p. 14 - 19, jun./ago. 2004. Disponível em: <http://iribnet.com.br/revista/reserva/revista317/317.pdf〉. Acesso em 30 jun 2020.

Os dez mandamentos para um cadastro moderno de bens imobiliários. In: CONGRESSO BRASILEIRO DE CADASTRO TÉCNICO MULTIFINALITÁRIO E GESTÃO TERRITORIAL, 2, 1996, Florianópolis. Anais. Florianópolis, UFSC, 1996. 
SANTOS, J.C. dos; FARIAS, E.S. de; CARNEIRO, A.F.T. Análise da Parcela como Unidade Territorial do Cadastro Urbano Brasileiro. Boletim de Ciências Geodésicas, Curitiba, v. 19, n. 4, p. 574-587, dez. 2013. Disponível em: 〈https://goo.gl/KEzh6w>. Acesso em: 30 jun. 2020. http://dx.doi.org/10.1590/S198221702013000400004 SANTOS, S. D. R. ; ANTUNES, A. F. B. . O Cadastro Territorial Multifinalitário no contexto dos processos de Regularização Fundiária Urbana. Revista Brasileira de Cartografia, v. 72, n. 2,2020 .

Disponível em: <http://www.seer.ufu.br/index.php/revistabrasileiracartografia/article/view/48360>. Acesso em 29 jun 2020. https://doi.org/10.14393/rbcv72n2-48360

\section{Biografias dos autores}
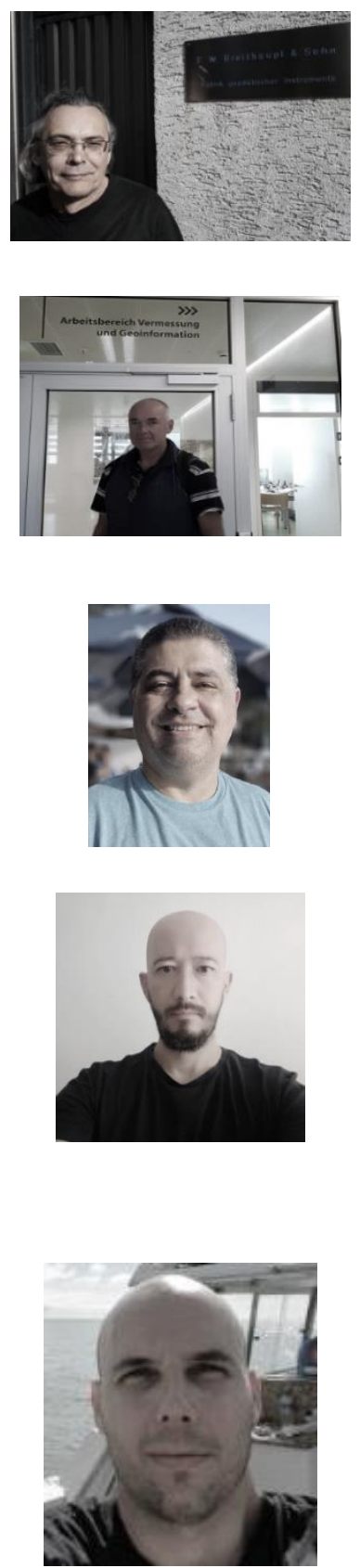

Cesar Rogério Cabral, Curitiba, 1960. Técnico em Estradas (ETFSC), Engenheiro Civil (UFSC), Mestre em Eng. De Transporte e Gestão Territorial (UFSC). Professor do Curso Técnico em Agrimensura do Instituto Federal de Santa Catarina (IFSC). Coordenador do Museu de Topografia Ênio Miguel de Souza. Membro da Comissão de Estudos de Topografia da ABNT.

Markus Hasenack, Três de Maio. Técnico em Agrimensura (IFSC), Tecnólogo em Construção Civil - Estradas e Topografia URI), Doutor em Engenharia Civil pela Universidade Federal de Santa Catarina (UFSC). Professor Titular do Curso Técnico em Agrimensura do Instituto Federal de Santa Catarina (IFSC). Membro da Comissão de Estudos de Topografia da ABNT.

Rovane Marcos de França, Tubarão, 1973. Técnico em Estradas (ETFSC), Técnico em Geomensura (CEFET/SC), Engenheiro Civil (UNISUL), Mestre em Engenharia Civil (UFSC), Doutorando em Ciências Geodésicas (UFPR). Professor do Curso Técnico em Agrimensura do Instituto Federal de Santa Catarina (IFSC). Membro da Comissão de Estudos de Topografia da ABNT.

Adolfo Lino de Araújo. Técnico em Agrimensura (IFSC), Engenheiro Civil (UFPB), Mestre em Engenharia Cartográfica (UFPE), Doutor em Engenharia Civil (UFSC). Membro da Comissão Nacional de Cartografia, Grupo de Trabalho sobre Cadastro. Atuou como membro da Comissão de Revisão da Portaria 511 do Ministério das Cidades sobre Cadastro Territorial Multifinalitário. Professor do Curso Técnico em Agrimensura do Instituto Federal de Santa Catarina (IFSC). Membro da Comissão de Estudos de Topografia da ABNT.

Flavio Boscatto, São Paulo. Técnico em Geomensura (CEFET/SC, atual IFSC). Doutor e Mestre em Engenharia Civil na área de Cadastro Técnico Multifinalitário e Gestão Territorial (UFSC) Engenheiro de Aquicultura (UFSC). Especialista e Licenciado em Docência para Educação Profissional (IFSC). Professor no Instituto Federal de Santa Catarina (IFSC) no Curso Técnico de Agrimensura. Membro da Comissão de Estudos de Topografia da ABNT. 